\title{
浙江古田山亚热带常绿阔叶林不同干扰强度下土壤呼吸 的日动态与季节变化
}

宁亚军 ${ }^{(12)}$, 陈世苹 ${ }^{(2)}$, 钱海源 ${ }^{(3)}$, 任海保 ${ }^{(2)}$, BEBBER Dan ${ }^{(4)}$, 陈建华 ${ }^{\left(1^{*}\right.}$

(1) 浙江师范大学化学与生命科学学院, 金华 321004;

(2) 中国科学院植物研究所, 植被与环境变化国家重点实验室, 北京 100093;

(3) 浙江古田山国家级自然保护区管理局, 开化 324300;

(4.) Earthwatch Institute, Mayfield House, Oxford OX2 7DE, UK

* 联系人, E-mail: sky78@zjnu.cn

2013-04-03 收稿, 2013-06-07 接受, 2013-10-17 网络版发表

国家自然科学基金(92209E2001)、Earthwatch Institute 国际合作项目和浙江省自然科学基金(Y5100361)资助

摘要 在浙江古田山常绿阔叶林区域选择了 4 个具代表性的不同干扰强度森林类型: 常绿阔叶 老龄林 $(\mathrm{OF})$ 、一次皆伐后自然恢复的天然次生林 I (SF I )、皆伐后自然恢复过程中经历一次重 度择伐的天然次生林 II (SF II)、人工杉木林 $(\mathrm{AF})$ 为研究对象, 进行了为期 1 年的土壤呼吸动态 监测, 定量分析了不同林型土壤呼吸的昼夜和季节变化，同时结合相关环境和生物因子的监 测，从日尺度和季节尺度上探讨了影响我国亚热带常绿阔叶林区不同森林土壤呼吸的主要驱 动因子, 并就不同的森林管理方式对亚热带森林土壤碳释放的可能影响做出了初步评估. 研究 发现 4 种林型土壤碳日累积释放量呈现显著的季节变化, 从 5 月份开始各林型土壤碳日累积释 放量以较快速率升高, 老龄林 8 月中旬达到最大, 次生林 I 在 7 月中旬达最大, 次生林 II 和人 工林在 6 月中旬达最大, 之后各林型持续下降到翌年 1 月份, 而后开始缓慢回升. 4 种林型年平 均土壤碳日累积释放量分别为 $1.48,1.48,1.51,0.87 \mathrm{~g} \mathrm{C} \mathrm{m}^{-2} \mathrm{~d}^{-1}$, 人工林的土壤碳日累积释放量 显著低于其他 3 种林型. 各林型的土壤呼吸速率的日变化幅度均不显著. 土壤表层温度是影响 该地区土壤呼吸季节动态的主要因素，二者呈显著的指数相关关系，相关系数 $R^{2}$ 为 $0.88 \sim 0.94$; 土壤表层含水量与土壤呼吸之间没有显著的相关关系。老龄林土壤温度敏感性 $\left(Q_{10}\right.$ 值) 显著高 于其他林型. 上述结果表明, 受干扰强度最大的人工林的土壤呼吸速率显著降低, 对温度变化 的敏感性显著降低; 受干扰强度相对较小的次生林其土壤呼吸速率和温度敏感性基本上和老 龄林保持一致. 古田山不同林型土壤呼吸季节变化的主要驱动因子均为土壤温度. 这些结论说 明不同干扰强度对亚热带森林土壤碳释放的影响不同, 这为精确估算该地区不同植被类型碳 收支提供了重要依据, 此外土壤呼吸无显著昼夜变化的结论将对该区域后续的动态监测工作 起到积极的指导作用.

在过去的 100 多年时间里，化石燃料的燃烧及土 地利用方式的改变等人类活动使得温室气体, 尤其 是 $\mathrm{CO}_{2}$ 气体含量剧增, 温室效应也越来越严重 ${ }^{[1,2]}$, 全球变暖已经成为人们面临的主要环境问题之一,
并且日益成为公众和科学家关注的热点 ${ }^{[3]}$. 因此了解 $\mathrm{CO}_{2}$ 在陆地生态系统中的吸收和排放过程与机理, 明 确陆地生态系统碳循环在全球碳循环过程中的作用 和贡献是非常重要的 ${ }^{[4]}$. 土壤是陆地碳循环最大的碳

引用格式: 宁亚军, 陈世苹, 钱海源, 等. 浙江古田山亚热带常绿阔叶林不同干扰强度下土壤呼吸的日动态与季节变化. 科学通报, 2013, 58: 3839-3848 Ning Y J, Chen S P, Qian H Y, et al. Diurnal and seasonal patterns of soil respiration in subtropical evergreen broad-leaved forests with different degrees of human disturbance in Gutianshan, Zhejiang Province (in Chinese). Chin Sci Bull (Chin Ver), 2013, 58: 3839-3848, doi: 10.1360/972013-389 
库 ${ }^{[5]}$. 森林生态系统是陆地生物圈的主要组成部分, 不仅本身维持着巨大的碳库，同时也维持着巨大的 土壤碳库 ${ }^{[6,7]}$. 森林生态系统土壤呼吸是土壤碳库向 大气中释放 $\mathrm{CO}_{2}$ 的一个重要过程, 是森林生态系统 碳循环的重要组成部分 ${ }^{[8 \sim 10]}$. 森林土壤碳储量的微小 变化将对大气 $\mathrm{CO}_{2}$ 浓度产生巨大的影响 ${ }^{[1]}$. 对森林 土壤呼吸时空变化格局及其生物环境影响因子的研 究显得尤为重要.

土壤呼吸指土壤释放 $\mathrm{CO}_{2}$ 过程, 主要包括根系 自养呼吸、微生物和土壤动物异养呼吸 ${ }^{[12]}$, 这些过程 主要受非生物因素(如土壤温度、土壤含水量、土壤养 分和土壤底物供给), 以及生物因素如植被状况、土壤 微生物和土壤动物的影响 ${ }^{[13]}$. 全球土壤呼吸释放 $\mathrm{CO}_{2}$ 量为 68 100 $\mathrm{Pg} \mathrm{C} \mathrm{a}^{-1[14,15]}$, 是化石燃料释放碳量 的 10 倍左右 ${ }^{[16]}$. 土壤呼吸是陆地生态系统与大气之 间碳交换的第二大通量组分 ${ }^{[17]}$, 中国区域土壤呼吸 的测定工作开始于 20 世纪 90 年代 ${ }^{[18]}$, 量化土壤呼吸 对评估全球森林生态系统碳平衡及碳收支具有重要 的意义.

我国亚热带常绿润叶林区面积近 250 万 $\mathrm{km}^{2}$, 生 物多样性丰富、结构复杂、类型多样, 对我们社会经 济发展和生态环境安全具有重要作用. 但由于长期 受到人类活动的干扰, 森林退化极为严重, 生态系统 功能遭到严重破坏. 从 20 世纪 80 年代后期, 在该地 区开始大规模的植树造林, 森林覆盖率得到不断提 高, 植被状况也得到了恢复, 但同时人类的森林经营 活动也加剧, 人类对森林的干扰更加频繁, 结果呈现 出森林干扰与恢复交叉进行, 导致亚热带区域碳源 与碳汇的估算存在很大的不确定性 ${ }^{[19,20]}$. 虽然近年 来中国区域的土壤呼吸研究逐渐增加 ${ }^{[21]}$, 但对亚热 带森林不同干扰强度下的土壤呼吸的研究相对较 少 ${ }^{[22 ~ 25]}$, 较长期的动态研究则更少, 如冯文婷等人 ${ }^{[26]}$ 对哀牢山具代表性中山湿性常绿阔叶林进行长达 1 年的季节间和昼夜间 (6 次)的土壤呼吸研究; 杨智杰 等人 ${ }^{[27]}$ 对福建建瓯市东门牛坑垅木荷、杉木、锥栗 等不同林型的土壤呼吸进行长达 1 年的日动态变化 研究; 田大伦等人 ${ }^{[28]}$ 对湖南天际岭林场樟树和枫香 林的土壤呼吸的动态研究; 王超等人 ${ }^{[29]}$ 对福建省万 木林保护区毛竹林土壤呼吸进行了为期 1 年的观察 研究, 上述研究得到了具有积极意义的结果, 但总体 而言, 尚存在取样面积不大 $($ 一般为若干 $20 \mathrm{~m} \times 20 \mathrm{~m}$ 样地), 植被类型不多, 日动态监测次数偏少, 未测
定生物因子, 未涉及固定样地等不足. 本研究以已建 成的浙江古田山 12 个 $1 \mathrm{hm}^{2}$ 固定样地为依托, 选择了 我国中亚热带常绿阔叶林区域具代表性的 4 种森林 类型为研究对象, 进行了为期 1 年的土壤呼吸动态监 测, 定量分析了不同干扰强度下不同林型土壤呼吸 的昼夜和季节变化, 同时结合土壤有机碳、土壤温 度、土壤含水量及微生物碳氮生物量等环境及生物因 子的监测, 分别从日尺度和季节尺度上探讨了影响 我国中亚热带常绿阔叶林土壤呼吸的主要驱动因子, 对不同干扰强度下亚热带森林土壤碳释放的变化规 律做出了综合评估, 为研究不同森林管理方式对中 亚热带森林土壤碳释放的可能影响提供了参考依据.

\section{1 材料与方法}

\section{1 研究区自然概况}

古田山国家级自然保护区 $\left(29^{\circ} 10^{\prime} 19.4^{\prime \prime}\right.$ $29^{\circ} 17^{\prime} 41.4^{\prime \prime} \mathrm{N}, 118^{\circ} 03^{\prime} 49.7^{\prime \prime} \sim 118^{\circ} 11^{\prime} 12.2^{\prime \prime} \mathrm{E}$ )位于浙江 省开化县西部的苏庄镇境内, 保护区总面积 $8107 \mathrm{hm}^{2}$, 属于中亚热带常绿阔叶林地带, 季风性气候区, 年平 均温度为 $15.3^{\circ} \mathrm{C}$, 最高月均温 $28.9^{\circ} \mathrm{C}$, 最低月均温 $4.1^{\circ} \mathrm{C}$, 年降水量 $1963.7 \mathrm{~mm}$, 年降雨天数大约为 $140 \mathrm{~d}$, 相对湿度为 $92.4 \%$, 年日照时数 $1747.5 \mathrm{~h}$, 无霜期约 为 $250 \mathrm{~d}$. 每年的 3 6月为第一雨季, 7 8 月为伏旱期, 8 月底 9 月受台风影响形成第二雨季, 10 月 次年 2 月 为干期. 土壤主要以黄壤和红壤土为主, 呈酸性 ${ }^{[30]}$ 植被类型主要有常绿阔叶林、常绿落叶阔叶混交林、 针叶阔叶混交林和针叶林 ${ }^{[31]}$.

\section{2 研究方法}

(i) 样地设置. 2008 2009 年中国科学院植物 研究所等单位在古田山自然保护区建立了 4 种不同 干扰强度的森林类型 $1 \mathrm{hm}^{2}$ 固定样地. (1) 常绿阔叶 老龄林 $(\mathrm{OF})$ : 位于保护区核心区内, 大于 100 年的自 然演替史, 基本上未经人为活动干扰. (2) 次生林 I (SF I ): 位于保护区缓冲区内, 约 50 年前全部砍伐, 然后自然更新恢复至今. (3) 次生林 II (SF II ): 位于 保护区缓冲区内, 50 年前皆伐后自然恢复, 约 20 年 前又经过一次重度择伐, 而后自然恢复至今. (4) 人 工林(AF)：位于保护区边界处，林龄约 20 年. 人工林 是将原有林木全部砍伐并经火烧清理后，人工种植上 杉木, 并在树木栽植过程中施加复合肥料, 为保证幼 
苗成活，在栽种后的前三年进行除草和适度疏伐 ${ }^{[32,33]}$. 2011 年 3 月 2012 年 7 月, 本研究组在上述不同 干扰强度的固定样地中选择 4 个代表性的 $1 \mathrm{hm}^{2}$ 样地, 进行了土壤呼吸日动态监测工作, 样地具体信息见 表 1 . 每个样地按 $20 \mathrm{~m}$ 间隔划分为 25 个小方格. 在 这 25 个小方格中随机设置 12 个方格作为土壤呼吸测 定点, 这 12 个测定点代表 12 个重复, 在每个测定点 安装一个 PVC 底座(内径 $20 \mathrm{~cm}$, 高 $11 \mathrm{~cm}$ ), 将 PVC 环一端削尖沿坡面压人土中约 $9 \mathrm{~cm}$ 深, 将 PVC 环内 的绿色植物齐地剪除, 安装过程中尽量减少对土壤 的扰动. 为了避免安装初期对土壤呼吸测量的可能 影响, 底座安装至少两周后才进行相关指标测定工 作, PVC 环内在整个测定期间位置保持不变化 ${ }^{[34]}$.

(ii) 土壤呼吸日变化的测定. 2011 年 4月 2012 年 7 月, 分别在每月下旬选择相对晴好的天气在 4 个 样地进行土壤呼吸日动态的测定. 每种林型每月测 定 1 次, 每次测定从早 8:00 至第二天早 8:00 持续 $24 \mathrm{~h}$, 每 $3 \mathrm{~h}$ 对每个样地的 12 个测定样点进行逐一测定, 每 个日动态共计 8 次测量. 其中, 2011 年 12 月和翌年 1 月由于天气寒冷, 土壤呼吸速率很低, 没有进行日动 态的监测工作, 仅在上午 9:00 左右对每个样地进行 了 1 次土壤呼吸的测量. 土壤呼吸测定采用 $\mathrm{Li}-8100$ 便携式土壤呼吸测定仪(Li-COR Inc, Nebraska, USA), 在测定的同时, 采用仪器自身配置的温度和水分探 头测定 $5 \mathrm{~cm}$ 深土层的土壤温度和土壤体积含水量. 2011 年 5 6 月由于土壤温度探头出现故障, 7 月由于 土壤水分探头出现故障, 没有获得相应有效的土壤 温度和土壤含水量同期测量数据.

本研究利用每个月测定的土壤呼吸速率日动态 数据推算出土壤呼吸日累积释放量. 另外, 通过分析 古田山不同林型土壤呼吸日动态数据, 发现上午 $8: 00 \sim 11: 00$ 的土壤呼吸速率和土壤呼吸日累积释放
量有明显的相关性，相关方程：

$$
R S \text { 日赫积 }=1.027 \times R s_{8: 00}+0.009\left(R^{2}=0.98, P<0.01\right),
$$

其中, $R s$ 日累积为土壤呼吸日累积释放量, $R s_{8: 00}$ 为早上 8:00 11:00 的土壤呼吸速率(见表3). 由此, 根据 2011 年 12 月和翌年 1 月上午 $8: 00 ~ 11: 00$ 的点测量数据推 测这两个月的日动态数据(其余月份均为实测).

(iii) 土壤采样及测定. 2011 年 8 月份, 在每个 样地的土壤呼吸测定底座附近 (距底座水平距离 $0.5 \sim 1 \mathrm{~m}$ 处), 用土钻(内径 $3.5 \mathrm{~cm}$ ) 钻取 $0 \sim 10 \mathrm{~cm}$ 深土 层的土壤样品. 为了减少空间异质性带来的影响, 每 个样品为 5 钻混合的样品. 样品混匀后置于封口袋中 带回实验室, 测定 $\mathrm{pH}$ 值. 每个土壤样品分为 2 份, 每 份重约 $50 \mathrm{~g}$, 其中 1 份去除根系后风干并粉碎, 进行 土壤有机碳和全氮的测定, 另 1 份 $4^{\circ} \mathrm{C}$ 低温保存, 进 行土壤微生物生物量碳和生物量氮含量的测定工作. 土壤 $\mathrm{pH}$ 采用 GB7859-87 方法测定; 有机碳含量采用 重铬酸钾外加热法; 土壤全氮含量采用凯氏定氮法 (Kjeltec 2200, Sweden Foss Company, Sweden). 土壤 微生物生物量碳、生物量氮含量采用氯仿熏蒸浸提法, 土壤浸提液中的有机碳含量采用 TOC 分析仪(LIQ TOC II/mutiNC3100, Elementar Analysensysteme GmbH, Hanau, Germany)测定 ${ }^{[35,36]}$.

(iv) 统计分析. 所有的统计分析都在 SPSS16.0 软件中进行, 用重复测量 One-way ANOVA 和多重比 较(Duncan test)检验不同森林类型的土壤呼吸、温度 和含水量之间的差异显著性, 用 One-way ANOVA 和 多重比较(Duncan test)检验各林型土壤指标之间的差 异显著性. 土壤呼吸与土壤温度之间的关系采用指 数模型拟合:

$$
R s=a \mathrm{e}^{b T},
$$

其中, $R s$ 为土壤呼吸速率 $\left(\mu \mathrm{mol} \mathrm{CO} \mathrm{CO}_{2}^{-2} \mathrm{~s}^{-1}\right), T$ 为 $5 \mathrm{~cm}$ 深的土壤温度, $a$ 为 $0^{\circ} \mathrm{C}$ 时的土壤呼吸速率, $b$ 为 $R s$ 的

\begin{tabular}{|c|c|c|c|c|}
\hline 森林类型 & 位置 & 海拔 $(\mathrm{m})$ & 平均胸径 $(\mathrm{cm})$ & 优势种 \\
\hline 老龄林 & $\begin{array}{r}118.19^{\circ} \mathrm{E} \\
29.28^{\circ} \mathrm{N}\end{array}$ & 742.8 & $4.56 \pm 0.06^{\mathrm{c}}$ & $\begin{array}{l}\text { 甜槠 (Castanopsis eyrei)、木荷 (Schima superba)、青 冈 } \\
\text { (Cyclobalanopsis glauca) }\end{array}$ \\
\hline 次生林 I & $\begin{array}{r}118.23^{\circ} \mathrm{E} \\
29.35^{\circ} \mathrm{N}\end{array}$ & 407.8 & $4.72 \pm 0.08^{b}$ & $\begin{array}{c}\text { 甜槠 (C. eyrei)、石栋 (Lithocarpus glaber)、木荷 }(\text { S. superba)、 } \\
\text { 青冈 }(\text { C. glauca)、米槠(Castanopsis carlesii) }\end{array}$ \\
\hline 次生林 II & $\begin{array}{r}118.14^{\circ} \mathrm{E} \\
29.33^{\circ} \mathrm{N}\end{array}$ & 391.8 & $3.85 \pm 0.03^{\mathrm{d}}$ & 甜槠 (C. eyrei)、石栋 (L. glaber) \\
\hline 人工林 & $\begin{array}{r}118.24^{\circ} \mathrm{E} \\
29.35^{\circ} \mathrm{N}\end{array}$ & 472.8 & $6.87 \pm 0.06^{\mathrm{a}}$ & 杉木(Cunninghamia lanceolata) \\
\hline
\end{tabular}

表 1 古田山 4 个不同管理方式样地的立地特征 ${ }^{\text {a) }}$

a) 同一列不同上标字母 $\mathrm{a}, \mathrm{b}, \mathrm{c}, \mathrm{d}$ 表示不同森林类型间差异显著 $(P<0.05)$ 
温度反应系数.

土壤呼吸温度敏感性 ( $Q_{10}$ 值)通过下面公式计算:

$$
Q_{10}=\mathrm{e}^{10 \mathrm{~b}},
$$

其中, $b$ 为 $R s$ 的温度反应系数 ${ }^{[24,34]}$.

\section{2 实验结果}

\section{1 环境因子的季节变化}

不同林型的 $5 \mathrm{~cm}$ 深处土壤温度季节变化趋势基 本一致, 呈现出明显的单峰曲线, 2 月份均达到最低, 随后持续上升, 7 到 8 月份均达到最高, 而后持续下 降(图 1(a)). 老龄林、次生林 I、次生林 II 、人工林全 年的土壤温度变化范围依次为: $3.97 \sim 24.33^{\circ} \mathrm{C}, 5.13 \sim$ $25.70^{\circ} \mathrm{C}, 5.56 \sim 25.98^{\circ} \mathrm{C}$ 和 $4.24 \sim 24.97^{\circ} \mathrm{C}$. 各林型的年 平均土壤温度依次为: $16.5^{\circ} \mathrm{C} \pm 0.02^{\circ} \mathrm{C}, 18.2^{\circ} \mathrm{C} \pm 0.01^{\circ} \mathrm{C}$, $18.4^{\circ} \mathrm{C} \pm 0.01^{\circ} \mathrm{C}$ 和 $17.2^{\circ} \mathrm{C} \pm 0.02^{\circ} \mathrm{C}, 2$ 种次生林的表层土 壤温度显著高于老龄林和人工林 $(P<0.05)$, 而次生林 之间差异不显著 $(P>0.05)$, 老龄林的最低, 且显著低 于人工林的土壤表层温度 $(P<0.05)$ (图 1(b)).
2012 年各林型 $5 \mathrm{~cm}$ 深处的土壤含水量显著高于 2011年的土壤含水量(图 1(c)). 2011年 5 11月和 2012 年 2 7 月老龄林、次生林 I 、次生林 II 和人工林的土 壤含水量变化范围依次为: 17\% 23\%, 12\% 23\%, 4\% 17\%, 8\% 24\%和 $22 \% \sim 43 \%, 24 \% \sim 40 \%, 17 \% \sim 33 \%$, 20\% 40\%. 老龄林的土壤含水量显著高于其他 3 种 林型 $(P<0.05)$, 次生林 I 和人工林之间差异不显著 $(P>0.05)$, 但均显著高于次生林 II $(P<0.05)$ (图 1(d)). 老龄林表层土壤 $(0 \sim 10 \mathrm{~cm})$ 的有机碳和全氮含量均显 著高于其他 3 种林型 $(P<0.05)$, 而其他 3 种林型之间 差异不显著 $(P>0.05)$, 其中老龄林的土壤有机碳含量 比其他 3 种林型的分别高 50\%, 44\%和 44\%, 土壤全 氮比其他 3 种林型的分别高 40\%，41\%和 44\%. 老龄 林、次生林 I 、次生林 II 和人工林土壤微生物生物量 碳依次为: $(0.318 \pm 0.050),(0.227 \pm 0.029),(0.190 \pm 0.031)$, $(0.213 \pm 0.013) \mathrm{g} \mathrm{kg}^{-1}$, 老龄林的土壤微生物生物量碳 显著高于其他 3 种林型 $(P<0.05)$, 其他 3 种林型之间 差异不显著 $(P>0.05)$. 土壤微生物生物量氮依次为: $(0.061 \pm 0.008),(0.040 \pm 0.006),(0.053 \pm 0.006),(0.039 \pm$
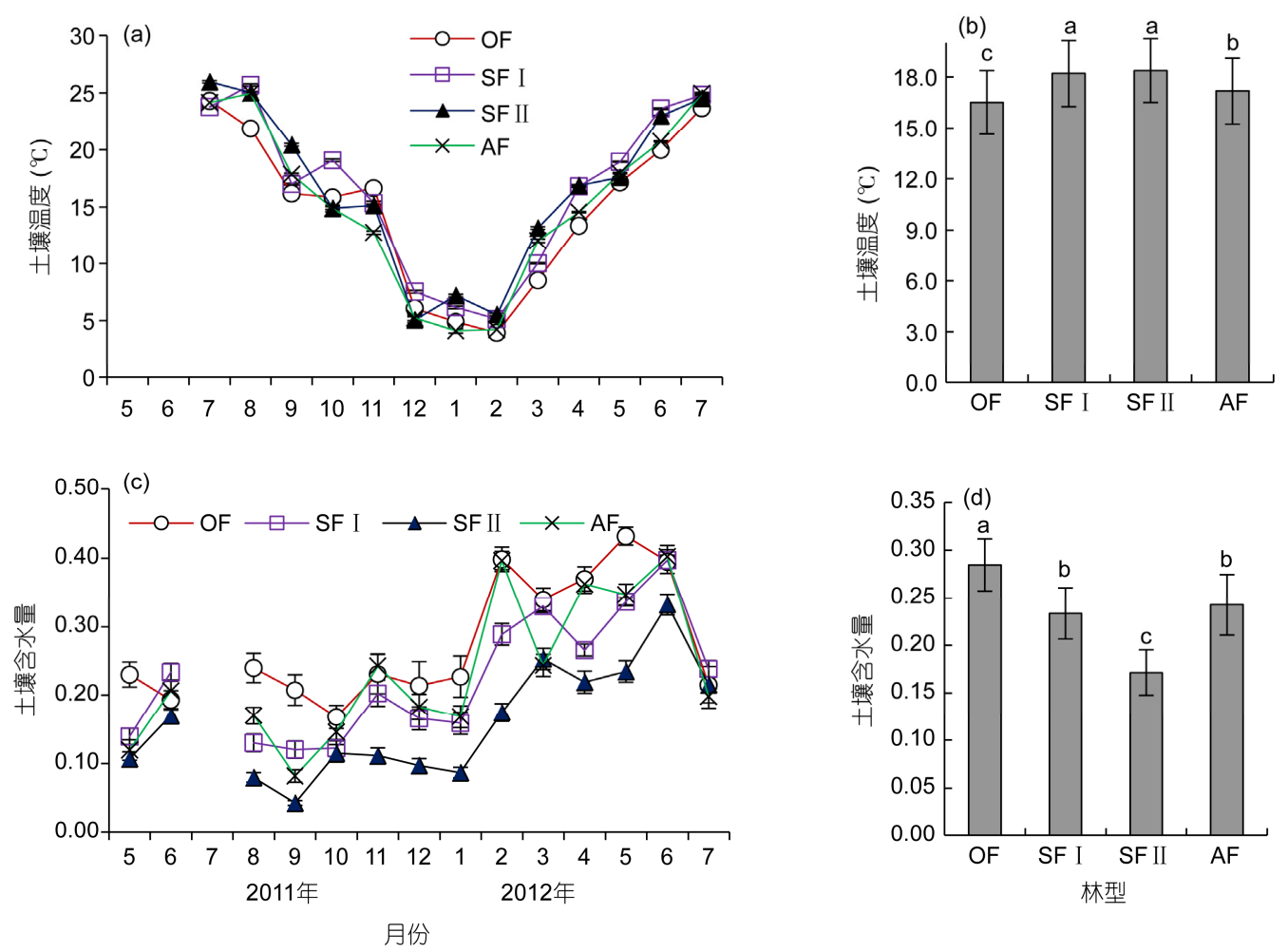

图 1 古田山 $\mathbf{4}$ 种不同林型表层 $\mathbf{5} \mathrm{cm}$ 深土壤温度 $(\mathrm{a}, \mathrm{c})$ 和土壤含水量 $(b, d)$ 的季节变化和年均值

平均值土标准差; (b) $n=12$, (d) $n=12, n$ 表示每个 $1 \mathrm{hm}^{2}$ 样地中的样本数; OF, 老龄林; SF I , 次生林 I ; SF II, 次生林 II ; AF, 人工林; 不同小写字 母表示差异显著 $(P<0.05) ; 2011$ 年 12 月及次年 1 月土壤温度和含水量数据为上午 9:00 的测量结果 
$0.004) \mathrm{g} \mathrm{kg}^{-1}$. 次生林 I 和人工林的土壤微生物生物 量氮显著低于老龄林 $(P<0.05)$, 而略低于次生林 II . 人工林和次生林 $\mathrm{I}$ 表层土壤的 $\mathrm{pH}$ 无显著差异 $(P>$ $0.05)$, 但均显著高于其他 2 种林型, 次生林 II 的 $\mathrm{pH}$ 显著高于老龄林(表 2).

\section{2 不同干扰强度下 4 种林型土壤呼吸的昼夜变化}

4 种林型的土壤表层温度(图 S1)和土壤呼吸速率 的昼夜变化(图 S2)均不明显, 波动很小, 尤其是冬季, 温度的一致性比土壤呼吸速率的一致性更好. 除人 工林以外其他 3 种林型的土壤呼吸速率在 6 11 月出 现较小波动, 且在该时间段内人工林的土壤呼吸速 率显著低于其他 3 种林型 $(P<0.05)$, 其他月份差异不 显著 $(P>0.05)$.

通过相关分析发现土壤碳日累积释放量与昼夜 间各时间段测定的土壤呼吸速率 $(R s)$ 均具有极显著 的线型相关 $(P<0.01), R^{2}$ 变化范围为 $0.97 \sim 0.99$, 直线 回归斜率 $(a)$ 为 $0.97 \sim 1$, 其中早上 8:00 11:00 的 $a$ 值 最高为 1 , 早上 $5: 00 \sim 8: 00$ 的 $a$ 值最低为 0.97 (表 3).

\section{3 不同干扰强度下土壤碳日累积释放量的季节 变化}

通过土壤呼吸日动态的测定结果, 本研究采用 累加法计算出土壤碳释放的日累积值. 老龄林、次生 林 I、次生林 II 及人工林的土壤碳日累积释放量呈现 明显的季节动态, 与土壤表层温度季节变化趋势一 致. 前 3 种林型的土壤碳日累积释放量从 5 月份开始
快速上升, 而人工林上升缓慢, 到夏季均达到最大值, 分别为 $2.57,2.44,2.12,1.46 \mathrm{~g} \mathrm{C} \mathrm{m}^{-2} \mathrm{~d}^{-1}$, 而后开始下 降至翌年 1 月份达到最低值, 随后又开始回升(图 2(a)). 4 种林型的年平均土壤碳日累积释放量分别为 $1.48,1.48,1.51,0.87 \mathrm{~g} \mathrm{C} \mathrm{m}^{-2} \mathrm{~d}^{-1}$, 人工林的土壤碳日 累积释放量显著低于其他 3 种林型 $(P<0.05)$, 其他 3 种林型差异不显著 $(P>0.05$ ) (图 2(b)). 人工林与其他 林型间土壤碳日累积释放量的差异主要表现在土壤 呼吸速率较高的 2011 年 6 月 10 月, 而在其他月份, 4 种林型的土壤碳日累积释放量之间均无显著差异 $(P>0.05)$.

\section{4 土壤呼吸与士壤温度和含水量关系}

4 种林型的土壤碳日累积释放量与表层的土壤 温度均呈极显著的指数相关关系 $(P<0.01)$, 且温度单 个因素可解释土壤呼吸作用季节变化 $88 \%$ \%4\%的变 异(图 3(a)). 4 种林型的 $Q_{10}$ 值分别为 3.12 $\pm 0.19,2.46 \pm$ $0.19,2.32 \pm 0.16,2.26 \pm 0.15$. 老龄林的 $Q_{10}$ 显著大于其 他 3 种林型 $Q_{10}$ 值 $(P<0.05)$. 其他 3 种林型 $Q_{10}$ 值虽有 随着干扰强度的增强呈依次减小的趋势, 但其差异 并未达到显著 $(P>0.05) .4$ 种林型的土壤碳日累积释 放量与表层土壤含水量之间没有显著的相关关系 $(P>0.05)$ (图 3(b)).

\section{3 讨论}

\section{1 土壤呼吸速率的昼夜变化}

古田山 4 种不同干扰强度林型的土壤呼吸速率

表 2 古田山 4 种不同林型表层土壤 $(0 \sim 10 \mathrm{~cm})$ 有机碳和全氮含量、 $\mathrm{pH}$ 及微生物生物量碳氮含量 ${ }^{\mathrm{a})}$

\begin{tabular}{|c|c|c|c|c|c|}
\hline 森林类型 & $\begin{array}{l}\text { 有机碳 } \\
\left(\mathrm{g} \mathrm{kg}^{-1}\right)\end{array}$ & $\begin{array}{c}\text { 全氮 } \\
\left(\mathrm{g} \mathrm{kg}^{-1}\right)\end{array}$ & $\mathrm{pH}$ & $\begin{array}{c}\text { 微生物生物量 } \\
\text { 碳 }\left(\mathrm{g} \mathrm{kg}^{-1}\right)\end{array}$ & $\begin{array}{c}\text { 微生物生物量 } \\
\text { 氮 }\left(\mathrm{g} \mathrm{kg}^{-1}\right)\end{array}$ \\
\hline 老龄林 & $63.4 \pm 6.7^{\mathrm{a}}$ & $1.89 \pm 0.02^{\mathrm{a}}$ & $4.47 \pm 0.037^{c}$ & $0.318 \pm 0.05^{\mathrm{a}}$ & $0.061 \pm 0.008^{\mathrm{a}}$ \\
\hline 次生林 I & $31.5 \pm 2.0^{\mathrm{b}}$ & $1.14 \pm 0.07^{\mathrm{b}}$ & $4.77 \pm 0.033^{\mathrm{a}}$ & $0.227 \pm 0.029^{b}$ & $0.040 \pm 0.006^{\mathrm{b}}$ \\
\hline 次生林 II & $35.5 \pm 1.7^{\mathrm{b}}$ & $1.12 \pm 0.06^{\mathrm{b}}$ & $4.61 \pm 0.027^{b}$ & $0.190 \pm 0.031^{\mathrm{b}}$ & $0.053 \pm 0.006^{\mathrm{ab}}$ \\
\hline 人工林 & $35.3 \pm 2.1^{\mathrm{b}}$ & $1.05 \pm 0.04^{\mathrm{b}}$ & $4.74 \pm 0.047^{\mathrm{a}}$ & $0.213 \pm 0.013^{\mathrm{b}}$ & $0.039 \pm 0.004^{\mathrm{b}}$ \\
\hline
\end{tabular}

a) 同一列不同字母表示不同森林类型间差异显著 $(P<0.05)$

表 3 古田山 4 种不同林型土壤碳日累积释放量与一天各时间段呼吸速率的相关关系 ${ }^{\text {a) }}$

\begin{tabular}{ccccccrrrr}
\hline 时间段 & $8: 00 \sim 11: 00$ & $11: 00 \sim 14: 00$ & $14: 00 \sim 17: 00$ & $17: 00 \sim 20: 00$ & $20: 00 \sim 23: 00$ & $23: 00 \sim 2: 00$ & $2: 00 \sim 5: 00$ & $5: 00 \sim 8: 00$ \\
\hline$R^{2}$ & 0.98 & 0.98 & 0.98 & 0.99 & 0.99 & 0.98 & 0.98 & 0.97 \\
$P$ & $<0.01$ & $<0.01$ & $<0.01$ & $<0.01$ & $<0.01$ & $<0.01$ & $<0.01$ & $<0.01$ \\
$a$ & 1.00 & 0.98 & 0.98 & 0.99 & 0.99 & 0.98 & 0.98 & 0.97 \\
\hline
\end{tabular}

a) 全部相关分析采用线性相关, $a$ 为线性相关方程的斜率 

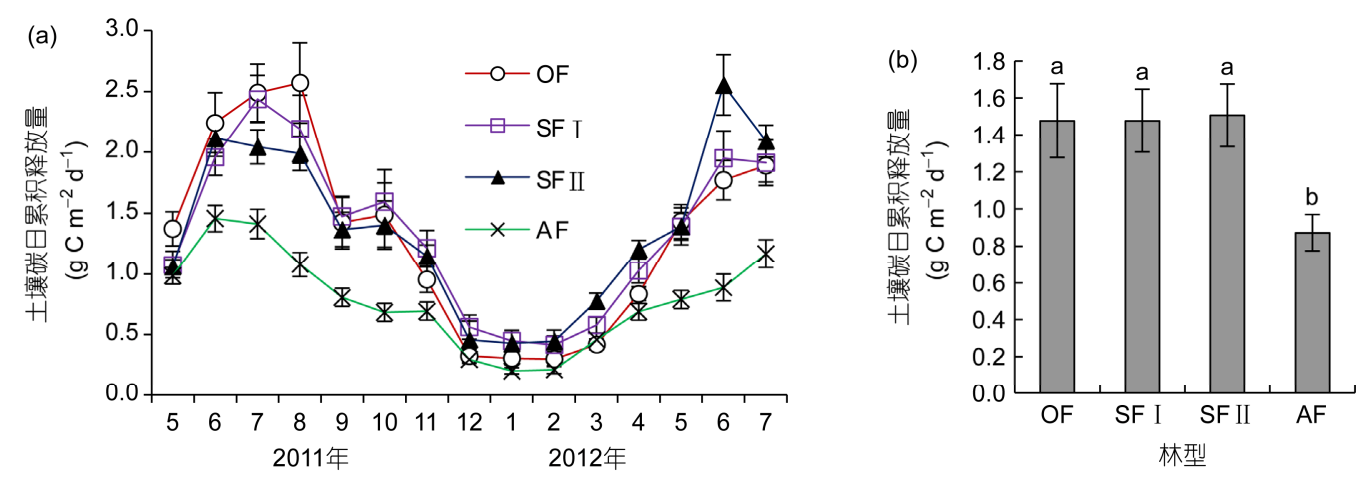

图 2 古田山 4 种不同林型土壤碳日累积释放量季节变化(a)及季节均值(b)

平均值标准差; (b) $n=12, n$ 表示每个 $1 \mathrm{hm}^{2}$ 样地中的样本数; 不同小写字母表示差异显著 $(P<0.05) ; 2011$ 年 12 月及次年 1 月土壤呼吸日累积释 放量数据是通过上午 9:00 测定的点测量数据推算的结果
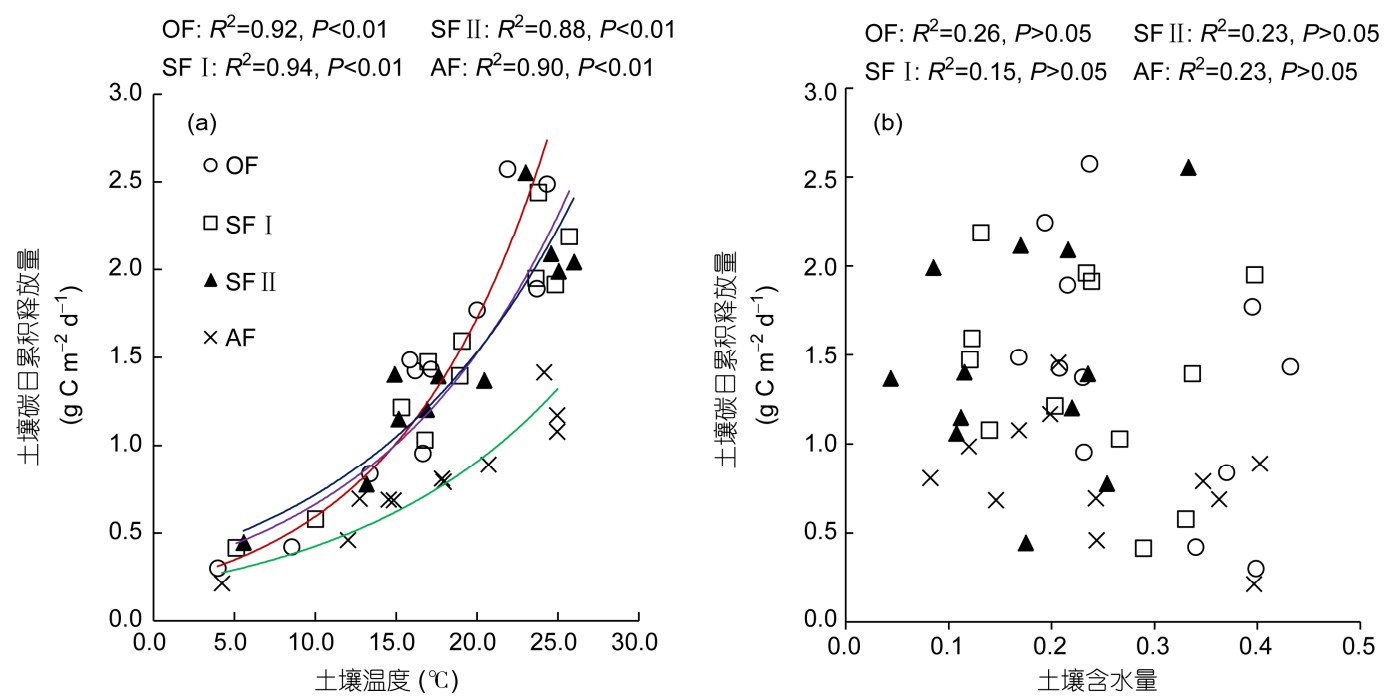

图 3 古田山 4 种不同林型土壤碳日累积释放量与土壤温度(a)和土壤含水量(b)之间的关系 图中的数据是每个月份的测量平均值; OF, 老龄林; SF I, 次生林 I ; SF II , 次生林 II ; AF, 人工林

在全年的昼夜波动都比较小，特别是冬季土壤呼吸 速率的日变化更加不明显, 这与林下稳定的土壤表 层温度密切相关. 尤其是冬季因昼夜间温差更小, 土 壤呼吸速率一致性更好. Yan 等人 ${ }^{[23]}$ 在鼎湖山不同演 替阶段常绿阔叶林土壤呼吸的日动态研究中也发现 了冬季各林型的土壤呼吸速率日变幅较小, 且松树 林的日变幅波动全年都比较小的结果. Yan 等人 ${ }^{[23]}$ 把 波动较小的原因归因于使用了不透明的测量室, 导 致日动态测定时忽略了林下植物的光合作用, 进而 导致土壤呼吸速率的昼夜变化不明显. 该结果与本 研究结果类似, 但文中的解释有待于商榷, 因为森林 土壤呼吸不应包括林下植物的光合作用. 亚热带常
绿阔叶林由于受季风影响, 降水丰沛, 森林冠层结构 复杂, 一般都有发育良好的乔木层和灌木层, 森林郁 闭度较大, 林下光照不足. 此外, 在受干扰较小的森 林中，一般地表还有很厚的枯枝落叶层，这可能导致 亚热带森林土壤表层温度昼夜变化不明显. 在本研 究中土壤温度最大日变化幅度仅有 $2.9^{\circ} \mathrm{C}$, 这就限制 了土壤呼吸的日变化幅度; Lopes de Gerenyu 等人 ${ }^{[37]}$ 在热带雨林中的研究与本研究结论相同, 因此认为 温度变幅小是导致土壤呼吸无显著昼夜变化的原因; Betson 等人 ${ }^{[38]}$ 在瑞典北部的云杉林的研究中也发现 了土壤呼吸无明显的日变化过程, 但主要的原因是 林下光照不足, 限制了光合作用对土壤呼吸的底物 
供给; 朱宁 ${ }^{[39]}$ 、盛浩 ${ }^{[40]}$ 对福建省建欧市万木林自然保 护区的浙江桂等 6 种天然常绿阔叶林, 以及当地天然 林、杉木人工林和坡耕地等土壤呼吸相关研究中也发 现了日变化不明显的现象. 另一方面, 冯文婷等人 ${ }^{[26]}$ 、

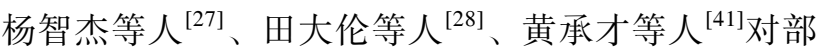
分亚热带地区的土壤呼吸日动态研究表明均有显著 的昼夜变化, 且多呈单峰型曲线. 上述情况表明对亚 热带森林土壤呼吸日动态的研究尚有不同的结果, 有待于进一步深人. 相对而言, 本研究结合已有固定 样地, 在取样面积、样本数量、植被类型选择、日动 态监测次数、可重复性等方面在中亚热带常绿阔叶林 地区具有较好的代表性, 研究结果对该区域的后续 研究将起到积极的指导作用.

\section{2 不同林型土壤碳日累积释放量的季节变化}

不同的土地利用方式对土壤呼吸速率有显著影 响 ${ }^{[42]}$, 本研究中老龄林、次生林 I 、次生林 II 及人工 林的土壤碳日累积释放量分别为 $1.48,1.48,1.51$, $0.87 \mathrm{~g} \mathrm{C} \mathrm{m}^{-2} \mathrm{~d}^{-1}$, 人工林的土壤碳日累积释放量比其 他林型低约为 $46 \%$. Sheng 等人 ${ }^{[43]}$ 对福建不同土地利 用方式下土壤呼吸的研究中发现人工林年均土壤呼 吸速率比原始林低近 $48.5 \%$, 是因为人工林的底物碳 供给较少、土壤有机碳和土壤全氮的可利用性较低 等. Yan 等人 ${ }^{[23]}$ 对鼎湖山不同演替阶段林型的土壤呼 吸研究中发现常绿阔叶林土壤呼吸日累积释放量 (3.19 $\left.\mathrm{g} \mathrm{C} \mathrm{m}^{-2} \mathrm{~d}^{-1}\right)$ 显著高于松树林( $\left.1.62 \mathrm{~g} \mathrm{C} \mathrm{m}^{-2} \mathrm{~d}^{-1}\right)$, 他把原因归因于松树林的林型单一, 且根系生物量 和土壤微生物量及地面调落物的分解较少, 结果释 放的 $\mathrm{CO}_{2}$ 量也较少. 在本研究中, 原始林的土壤有机 碳和土壤全氮及微生物生物量碳氮均显著高于杉木 人工林(表 2 ), 随着干扰强度的减弱, 由于土壤碳输 人增加, 底物供给越来越充足, 微生物量越来越多, 调落物和土壤有机质的分解加快, 碳的释放量增加.

\section{3 土壤呼吸日变化和季节变化的主要驱动因子}

很多研究表明, 土壤温度和水分是控制土壤呼 吸速率时空变化最主要的 2 个因素 ${ }^{[44 \sim 48]}$. 古田山不 同干扰类型森林连续 1 年的监测数据表明, 不同林型 $5 \mathrm{~cm}$ 深处的土壤温度与碳日累积释放量的季节变化 都具有极显著的指数关系 $(P<0.01)$, 土壤温度可以解 释 88\% 94\%土壤呼吸的季节波动(图 3(a)). 这和其他
亚热带森林样地土壤呼吸研究结果一致 ${ }^{[49 \sim 51]}$, 说明 土壤表层温度变化是亚热带地区土壤呼吸季节变化 的主要驱动因子 ${ }^{[52]}$.

古田山不同林型土壤呼吸温度敏感性 ( $Q_{10}$ 值)的 变化幅度和亚热带地区大多数研究结果类似 ${ }^{[23,34,43]}$, 但从 $Q_{10}$ 值的变化趋势看, 随着干扰强度的增强, 古 田山地区不同森林类型土壤呼吸对温度的敏感性依 次减小, 这与很多随着干扰强度增强温度敏感性增 大的研究结论不同 ${ }^{[23,43,53]}$, 仅和韩天丰等人 ${ }^{[24]}$ 对鼎 湖山马尾松林-针阔叶混交林-季风常绿阔叶林土壤 呼吸和温度的研究结果类似. $\mathrm{Q}_{10}$ 受诸多生物因素和 非生物因素的影响 ${ }^{[17,54]}$, 古田山区不同森林类型 $Q_{10}$ 值和干扰强度负相关的原因可能是老龄林的土壤有 机碳和全氮及微生物生物量碳氮含量显著高于其他 3 种林型, 受干扰后的森林生态系统中土壤底物供给 能力和微生物量都明显降低, 使得其对温度响应的敏 感性降低, 深层次的原因还需进一步的研究.

古田山不同干扰类型森林连续 1 年的监测数据 表明, 4 种林型的土壤碳日累积释放量与表层土壤含 水量之间没有显著的相关关系 $(P>0.05)$ (图 3(b)), 本 研究区域内降水丰沛, 年平均降雨量近 $2000 \mathrm{~mm}$, 水 分可能不是土壤微生物活动的限制性因子 ${ }^{[50]}$, 罗璐等 人 $^{[34]}$ 在神农架不同海拔梯度典型森林, Iqbal 等人 ${ }^{[42,55]}$ 在我国湖北咸宁等亚热带地区的研究中也发现的相 似的结果.

综上所述, 通过连续 1 年的监测数据表明, 土壤 温度是决定古田山不同林型土壤呼吸季节变化的最 主要因子. 在日尺度上, 由于较为稳定的土壤表层温 度，各林型土壤呼吸都没有明显的日变化格局，这 一结果将用于指导本地区后续的土壤呼吸动态监测 工作.

本研究以已建成的浙江古田山固定样地为依托, 选取了不同干扰强度下 4 种林型的 4 个 $1 \mathrm{hm}^{2}$ 固定样 地进行了 1 年的土壤呼吸动态监测, 并同时取样分析 了采样点周围的土壤相关指标，获得了比较完整的 土壤呼吸日动态数据，由此估算了该地区的土壤碳 日累积释放量, 此外还探讨了生物因素和非生物因 素, 尤其是土壤表层温度和水分对土壤呼吸的影响, 本研究为精确估算该地区不同干扰强度下植被类型 土壤碳收支，为了解该地区不同类型森林土壤碳排 放过程和机理提供了重要依据. 

学及工人师傅.

\section{参考文献}

1 沙丽清, 郑征, 唐建维, 等. 西双版纳热带季节雨林的土壤呼吸. 中国科学 D 辑：地球科学, 2004, 34 (增刊 II ): 167-174

2 朴世龙，方精云，黄耀. 中国陆地生态系统碳收支. 中国基础科学, 2010, 6: 20-23

3 Gates D M. Climate Change and Its Biological Consequences. Sunderland: Sinauer Associates Inc, 1993

4 周广胜, 王玉辉, 蒋延玲, 等. 陆地生态系统类型转变与碳循环. 植物生态学报, 2002, 26: 250-254

5 Raich J W, Potter C S, Bhagawati D. Interannual variability in global soil respiration. Glob Change Biol, 2002, 8: 800-812

6 Liu J, Jiang P K, Wang H L, et al. Seasonal soil $\mathrm{CO}_{2}$ efflux dynamics after land use change from a natural forest to Moso bamboo plantations in subtropical China. For Ecol Manage, 2011, 262: 1131-1137

7 Gong J R, Ge Z W, An R, et al. Soil respiration in poplar plantations in northern China at different forest ages. Plant Soil, 2012, 360: $109-122$

8 Woodwell G M, Whitaker R H, Reiners W A, et al. Biota and world carbon budget. Science, 1978, 199: 141-146

9 Bond-Lamberty B, Thomson A. Temperature-associated increases in the global soil respiration record. Nature, 2010, 464: 579-583

10 Schimel D S, House J I, Hibbard K A, et al. Recent patterns and mechanisms of carbon exchange by terrestrial ecosystems. Nature, 2001, 414: $169-172$

11 Fu S L, Cheng W X, Susfalk R. Rhizosphere respiration varies with plant species and phenology: A greenhouse pot experiment. Plant Soil, 2002, 239: 133-140

12 Tang J W, Baldocchi D D. Spatial-temporal variation in soil respiration in an oak-grass savanna ecosystem in California and its partitioning into autotrophic and heterotrophic components. Biogeochemistry, 2005, 73: 183-207

13 Kretzschmar A, Ladd J N. Decomposition of ${ }^{14} \mathrm{C}$-labeled plant material in soil: the influence of substrate location, soil compaction and earthworm numbers. Soil Biol Biochem, 1993, 25: 803-809

14 Musselman R C, Fox D G. A review of the role of temperate forests in the global CO 2 balance. J Air Waste Manage, 1991, 41: 798-807

15 Raich J W, Schlesinger W H. The global carbon dioxide flux in soil respiration and its relationship to vegetation and climate. Tellus, 1992 , 44B: 81-99

16 Raich J W, Potter C S. Global patterns of carbon dioxide emissions from soils. Glob Biogeochem Cycle, 1995, 9: 23-36

17 Davidson E A, Janssens I A, Luo Y Q. On the variability of respiration in terrestrial ecosystems: Moving beyond Q ${ }_{10}$. Glob Change Biol, 2006, 12: 154-164

18 刘绍辉, 方精云. 土壤呼吸的影响因素及全球尺度下温度的影响. 生态学报, 1997, 17: 469-476

19 宋永昌, 陈小勇, 王希华. 中国常绿阔叶林研究的回顾与展望. 华东师范大学学报(自然科学版), 2005, 1: 1-8

20 辛勤, 刘源月, 刘云斌. 中国亚热带森林土壤呼吸的基本特点. 成都大学学报(自然科学版), 2010, 29: 32-35

21 展小云, 于贵瑞, 郑泽梅, 等. 中国区域陆地生态系统土壤呼吸碳排放及其空间格局——基于通量观测的地学统计评估. 地球科学 进展, 2012, 31: 97-108

22 方精云, 王娓. 作为地下过程的土壤呼吸: 我们理解了多少? 植物生态学报, 2007, 31: 345-347

23 Yan J H, Zhang D Q, Zhou G Y, et al. Soil respiration associated with forest succession in subtropical forests in Dinghushan Biosphere Reserve. Soil Biol Biochem, 2009, 41: 991-999

24 韩天丰，周国逸，李跃林，等. 中国南亚热带森林不同演替阶段土壤呼吸的分离量化. 植物生态学报, 2011, 35: 946-954

25 郭明，康蒙，仲强，等. 浙江天童森林退化和受损对土壤呼吸的影响. 华东师范大学学报(自然科学版), 2011, 4: 53-60

26 冯文婷, 邹晓明, 沙丽清, 等. 哀牢山中山湿性常绿阔叶林土壤呼吸季节和昼夜变化特征及影响因子比较. 植物生态学报, 2008, 32: 31-39

27 杨智杰, 陈光水, 黄石德, 等. 中亚热带山区不同土地利用方式土壤呼吸的日动态变化. 亚热带资源与环境学报, 2009, 4: 39-45

28 田大伦, 王光军, 间文德，等. 亚热带樟树和枫香林土壤呼吸动态特征. 科学通报, 2009, 54: 2437

29 王超，杨智杰，陈光水，等. 万木林保护区毛竹林土壤呼吸特征及影响因素. 应用生态学报, 2011, 22: 1212-1218

30 楼炉焕, 金水虎. 浙江古田山自然保护区种子植物区系分析. 北京林业大学学报, 2000, 22: 33-39

31 于明坚, 胡正华, 余建平, 等. 浙江古田山自然保护区森林植被类型. 浙江大学学报(农业与生命科学版), 2001, 27: 375-380

32 马克平. 监测是评估生物多样性保护进展的有效途径. 生物多样性, 2011, 19: 125-126

33 宋凯，米湘成，贾琪，等. 不同程度人为干扰对古田山森林群落谱系结构的影响. 生物多样性, 2011, 19: 190-196 
34 罗璐，申国珍，谢宗强，等. 神农架海拔梯度上 4 种典型森林的土壤呼吸组分及其对温度的敏感性. 植物生态学报, 2011,35 : $722-730$

35 鲁如坤. 土壤农业化学分析方法. 北京: 中国农业科技出版社, 1999

36 刘占峰, 刘国华, 傅伯杰, 等. 人工油松林(Pinus tabulaeformis)恢复过程中土壤微生物生物量 C、 N 的变化特征. 生态学报, 2007, 27: $1011-1018$

37 Lopes de Gerenyu V O, Kurbatova Y A, Kurganova I N, et al. Daily and seasonal dynamics of $\mathrm{CO}_{2}$ fluxes from soil under different stands of Monsoon tropical forest. Eurasian Soil Sci, 2011, 44: 984-990

38 Betson N R, Göttlicher S R, Hall M, et al. No diurnal variation in rate or carbon isotope composition of soil respiration in a boreal forest. Tree Physiol, 2007, 27: 749-756

39 朱宁. 中亚热带不同常绿阔叶林群落土壤呼吸及其影响因素研究. 硕士学位论文. 福州: 福建师范大学, 2010

40 盛浩. 中亚热带山区土壤呼吸及其组分对土地利用变化的响应. 博士学位论文. 福州：福建师范大学, 2010

41 黄承才, 葛泳, 常杰, 等. 中亚热带东部三种主要木本群落土壤呼吸的研究. 生态学报, 1999, 19: 324-328

42 Iqbal J, Hu R G, Du L J, et al. Differences in soil $\mathrm{CO}_{2}$ flux between different land use tyes in mid-subtropical China. Soil Biol Biochem, 2008, 40: 2324-2333

43 Sheng H, Yang Y S, Yang Z J, et al. The dynamic response of soil respiration to land-use changes in subtropical China. Glob Change Biol, 2010, 16: 1107-1121

44 Buchmann N. Biotic and abiotic factors controlling soil respiration rates in Pieca abies stands. Soil Biol Biochem, 2000, 32: 1625-1635

45 Fang C, Moncrieff J B . The dependence of soil $\mathrm{CO}_{2}$ efflux on temperature. Soil Biol Biochem, 2001, 33: 155-165

$46 \mathrm{Xu} \mathrm{M}$, Qi Y. Soil-surface $\mathrm{CO}_{2}$ efflux and its spatial and temporal variations in a young ponderosa pine plantation in northern California. Glob Change Biol, 2001, 7: 667-677

47 Kiese R, Butterbach-Bahl K. $\mathrm{N}_{2} \mathrm{O}$ and $\mathrm{CO}_{2}$ emissions from three different tropical forest sites in the wet tropics of Queensland, Australia. Soil Biol Biochem, 2002, 34: 975-987

48 Gough C M, Seiler JR. The influence of environmental, soil carbon, root, and stand characteristics on soil $\mathrm{CO}_{2}$ efflux in loblolly pine (Pinus taeda L.) plantations located on the South Carolina Coastal Plain. For Ecol and Manage, 2004, 191: 353-363

49 韩广轩, 周广胜. 土壤呼吸作用时空动态变化及其影响机制研究与展望. 植物生态学报, 2009, 33: 197-205

50 Lou Y S, Li Z P, Zhang T L. Carbon dioxide flux in a subtropical agricultural soil of China. Water Air Soil Pollut, 2003, 149: 281-293

51 Tang X L, Liu S G, Zhou G Y, et al. Soil-atmospheric exchange of $\mathrm{CO}_{2}, \mathrm{CH}_{4}$ and $\mathrm{N}_{2} \mathrm{O}$ in three subtropical forest ecosystems in southern China. Glob Change Biol, 2006, 12: 546-560

52 Wang W, Peng S S, Wang T, et al. Winter soil $\mathrm{CO}_{2}$ efflux and its contribution to annual soil respiration in different ecosystems of a foreststeppe ecotone, North China. Soil Biol Biochem, 2010, 42: 451-458

53 Tang X L, Zhou G Y, Liu S G, et al. Dependence of soil respiration on soil temperature and soil moisture in successional forests in southern China. Acta Botan Sin, 2006, 48: 654-663

54 Fierer N, Colman B P, Schimel J P, et al. Predicting the temperature dependence of microbial respiration in soil: A continental-scale analysis. Glob Biogeochem Cycle, 2006, 20, doi: 10.1029/2005GB002644

55 Iqbal J, Hu R G, Feng M L, et al. Microbial biomass, and dissolved organic carbon and nitrogen strongly affect soil respiration in different land use: A case study at three gorges reservoir area, South China. Agr Ecosyst Environ, 2010, 137: 294-307 


\title{
Diurnal and seasonal patterns of soil respiration in subtropical evergreen broad-leaved forests with different degrees of human disturbance in Gutianshan, Zhejiang Province
}

\author{
NING YaJun ${ }^{1,2}$, CHEN ShiPing ${ }^{2}$, QIAN HaiYuan ${ }^{3}$, REN HaiBao $^{2}$, BEBBER Dan $^{4} \&$ CHEN JianHua $^{1}$ \\ ${ }^{1}$ College of Chemistry and Life Sciences, Zhejiang Normal University, Jinhua 321004, China; \\ ${ }^{2}$ State Key Laboratory of Vegetation and Environmental Change, Institute of Botany, Chinese Academy of Sciences, Beijing 100093, China; \\ ${ }^{3}$ Gutianshan National Nature Reserve Administrative Bureau, Kaihua 324300, China; \\ ${ }^{4}$ Earthwatch Institute, Mayfield House, Oxford, OX2 7DE, UK
}

The aims of this study were to investigate the diurnal and seasonal variations in soil respiration in different broad-leaved forest types with different degrees of human disturbance, to identify the major abiotic and biotic factors affecting the daily and seasonal patterns of soil respiration, and to evaluate the effects of different forest management types and human disturbance on soil respiration in subtropical forests. We selected four different $1 \mathrm{hm}^{2}$ forests with different degrees of human disturbance in Gutianshan, Zhejiang Province: An old-growth forest (OF, almost no human disturbance); two secondary forests (SF1, a secondary forest regrown after clear cutting about 50 years ago, and SF2, a secondary forest regrown after clear cutting about 50 years ago and selective cutting about 20 years ago); and a plantation forest (AF, planted about 20 years ago). We measured the diurnal and seasonal changes in soil respiration rates in each plot every month from May 2011 to July 2012. We also measured soil temperature and water content of the surface soil layer during sampling. The annual means of daily accumulated soil carbon release were $1.48,1.48,1.51$, and $0.87 \mathrm{~g} \mathrm{C} \mathrm{m}^{-2} \mathrm{~d}^{-1}$ in $\mathrm{OF}$, $\mathrm{SF} 1, \mathrm{SF} 2$, and AF plots, respectively. The soil respiration rate in AF was significantly lower than those in the other three forest types. On the diurnal scale, there were no significant variations in soil respiration rates among the four forest types. Our results indicated that the rate of soil respiration measured any time during the day can be used to predict daily accumulated soil carbon release. Significant positive relationships were found between soil respiration and surface soil temperature $\left(R^{2}=0.88-0.94\right)$ for all four forest types. There were no significant relationships between soil respiration and soil water content. The $\mathrm{Q}_{10}$ value of $\mathrm{OF}$ was significantly higher than those of the other three forest types. The results showed that the soil respiration rate and its sensitivity to temperature were significantly decreased in the plantation with the most intense human disturbance (AF). The soil respiration rates and $\mathrm{Q}_{10}$ values of both SF forests were similar to those of OF forest. Soil temperature was the most important driving factor for soil respiration. Together, our results implied that different degrees of human disturbance had different effects on soil respiration in these forests. This information is important to estimate the role of human interference in regional carbon cycles. Also, the finding that there was no significant variation in the diurnal soil respiration rates is very important for guiding further research on soil respiration in related regions.

subtropical evergreen broad-leaved forest, old growth forest, secondary forest, plantation, soil respiration, soil temperature doi: $10.1360 / 972013-389$

\section{补充材料}

图 S1 古田山 4 种不同林型土壤表层温度的昼夜变化

图 S2 古田山 4 种不同林型土壤呼吸速率的昼夜变化

本文的以上补充材料见网络版 csb.scichina.com. 补充材料为作者提供的原始数据, 作者对其学术质量和内容负责. 


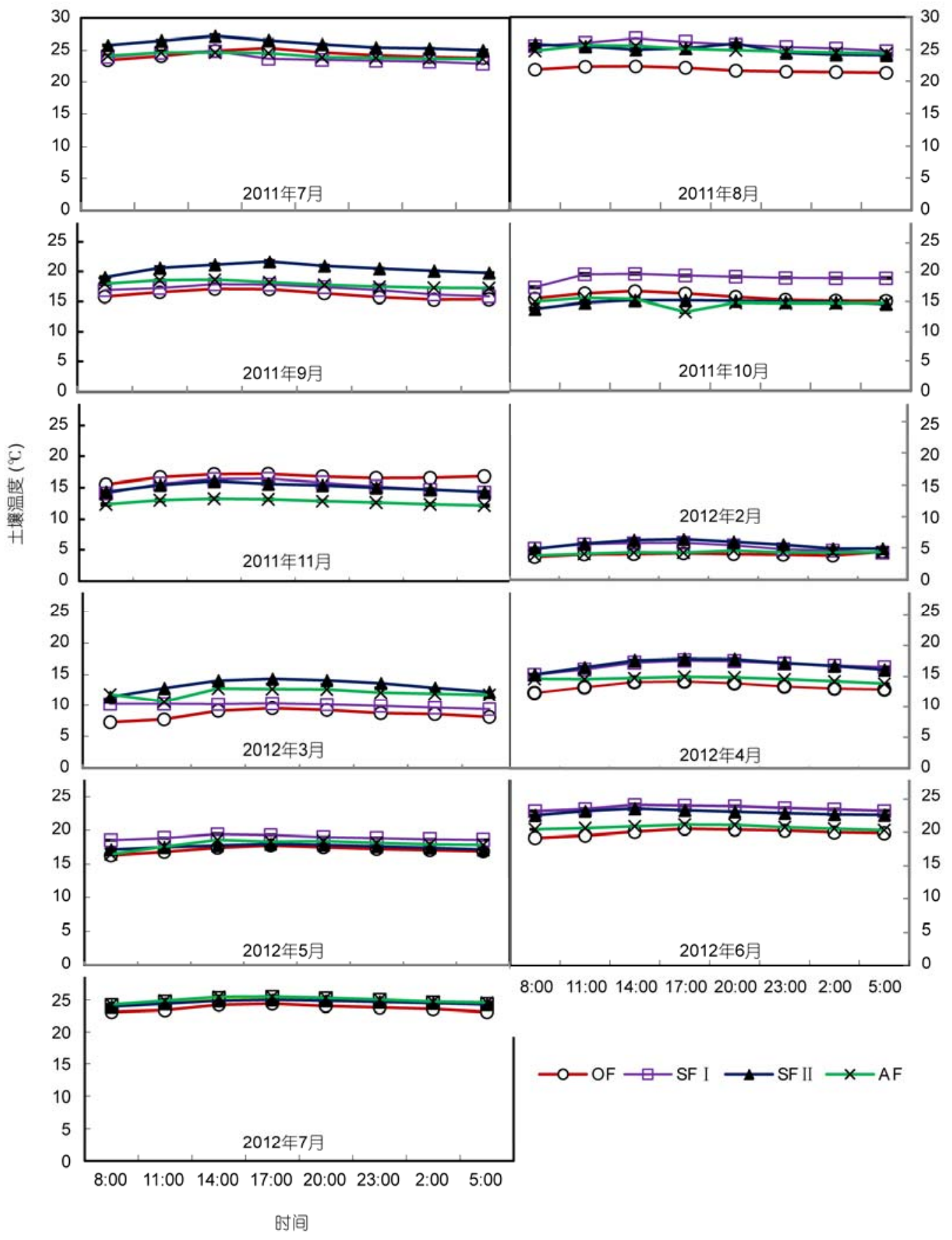

图 S1 古田山 4 种不同林型土壤表层温度的昼夜变化 


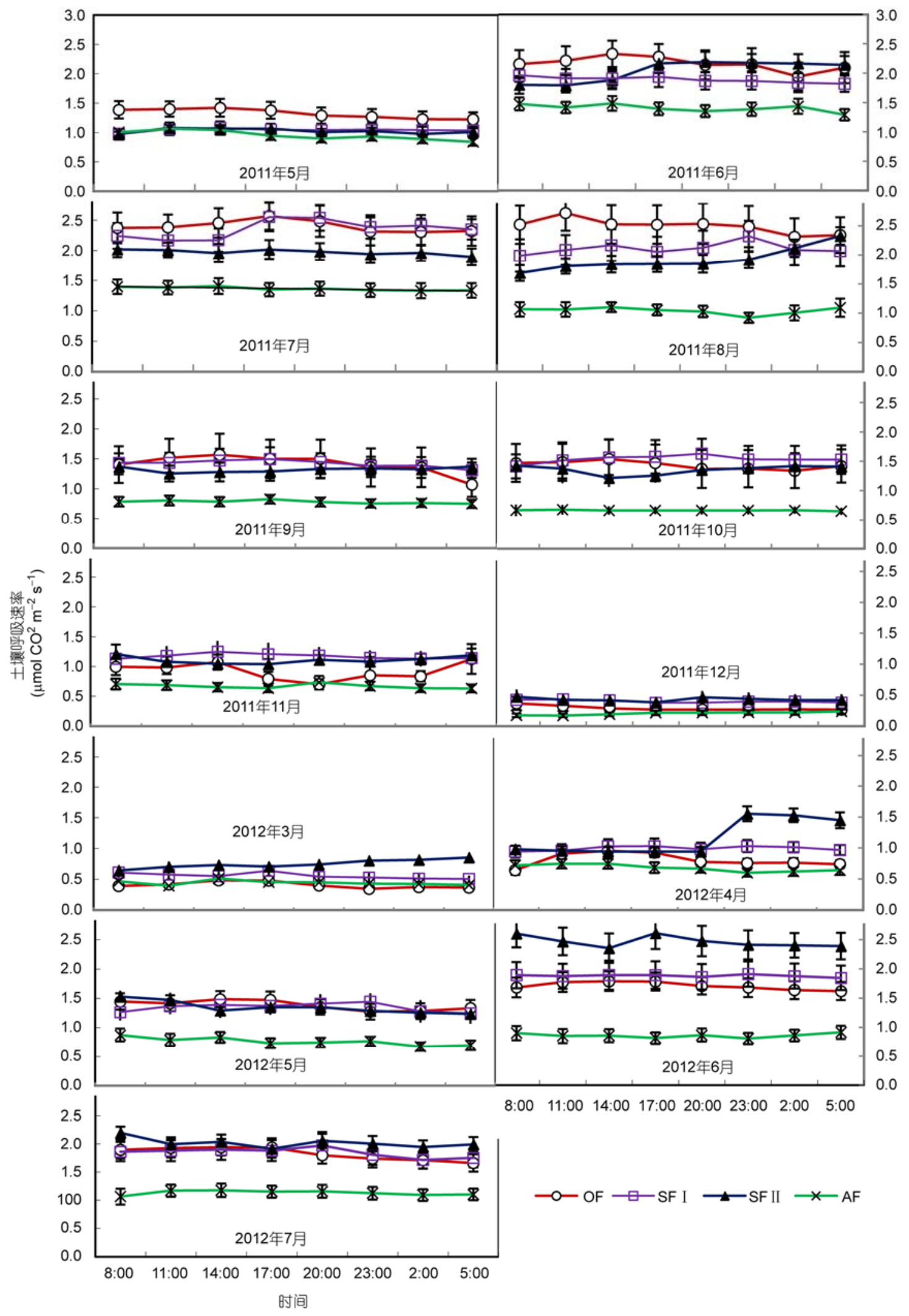

图 S2 古田山 4 种不同林型土壤呼吸速率的昼夜变化 